\title{
A Customer Satisfaction Model for Effective Fast Fashion Store Service
}

\author{
Tomomi Nonaka ${ }^{*}$, Mitsuru Igarashi, and Hajime Mizuyama \\ Dept. of Industrial and Systems Engineering, Aoyama Gakuin University, \\ 5-10-1 Fuchinobe, Chuo-ku Sagamihara-shi, Kanagawa 252-5258, Japan \\ nonaka@ise.aoyama.ac.jp
}

\begin{abstract}
This paper proposed a customer satisfaction model to effectively manage staff priorities and service at fast fashion stores. An evaluation model of customer satisfaction was developed through multiple regression analysis of two measures. The first measure considered the difference between actual times and perceived times of customers' behavioural processes while shopping to determine whether or not customers felt dissatisfied. The second measure identified factors which led to customer frustration through a multiple choice questionnaire. The proposed model was applied to multi-agent simulation to compare customer satisfaction levels.
\end{abstract}

Keywords: customer satisfaction, multiple regression analysis, multi-agent, perceived time.

\section{Introduction}

The service sector plays a key role in economic activity and the creation of employment opportunities in developed as well as developing countries. The growth of the fashion retail industry, which is part of the service sector, has been increasing as new industry players called 'fast fashion retailers' enter the scene. Fast fashion is used to refer to retailers with strategies to adopt current and emerging trends quickly and effectively [1]. They sell clothes and provide related services at their stores, which is categorised as a business to customer (B to C) service. The importance of customer satisfaction in B to $\mathrm{C}$ service has been widely recognised, as it has been found to be a significant determinant of repeat sales, positive word of mouth, and consumer loyalty [2]. Many studies have investigated the relationship between service quality and customer satisfaction [3][4][5][6], where it has been demonstrated [5] that these variables are independent but closely related.

To increase customer satisfaction and, at the same time, be profitable, it is necessary to provide quality service with limited human resources. Therefore, strict task prioritisations and staff assignments are often employed in fast fashion stores. The rules, which are often founded according to customer-first philosophies and prior

\footnotetext{
* Corresponding author.

B. Grabot et al. (Eds.): APMS 2014, Part II, IFIP AICT 439, pp. 587-594. 2014.

(C) IFIP International Federation for Information Processing 2014
} 
experience, may make it difficult to adapt to fluctuating customer demands. Furthermore, the effects of prioritisation on customer satisfaction have not yet been revealed.

Thus, a model to evaluate customer satisfaction should be applied to effectively manage task priorities. Customer satisfaction has been evaluated by measuring the customer wait experience [7]-[15], which is described as a pervasive and often unavoidable experience that appears to be a strong determinant of overall satisfaction [9][13]. A negative correlation between wait times and overall customer satisfaction has been shown [15][16]; when time spent waiting increases, satisfaction in general decreases [13][14]. Following these findings, actual wait times compared with perceived wait times have been introduced as indicators of customer satisfaction [8][11][12][15]. An earlier study [8] measured both actual and perceived customer wait times, and then compared these before and after a process change. The effects of a process change on customers' perceptions of wait times and customer satisfaction have also been examined. An earlier study [11] measured the actual and perceived wait times at a restaurant, and found that perceived wait times became shorter with the introduction of a digital signage system that provided interesting menu-related information to customers while waiting for their orders to arrive.

In the aforementioned studies, customer satisfaction has only been evaluated in select situations. However, assessing overall customer satisfaction is needed in order to control staff task prioritisation and improve service quality. Thus, this study proposes a customer satisfaction model using multiple regression analyses of two measures. The first measure was the difference between actual and perceived times spent at each stage of the customer's behavioural process, which indicated the degree of customer dissatisfaction throughout the shopping experience. The second measure aimed to identify key factors which led to customer frustration through a multiple choice questionnaire. The proposed model was then incorporated into a multi-agent simulation to examine customer satisfaction potentials related to different managerial methods under various conditions.

The remainder of this paper will propose an evaluation model and introduce a method to measure customer satisfaction. The paper will then test this proposed model on customer satisfaction levels through a multi-agent simulation analysis. Following the results, the discussion and conclusions are provided.

\section{Customer Satisfaction Model}

The proposed customer satisfaction model considers the difference between actual and perceived times [8][11][12][15] during the behavioural process of customers at a store as an evaluation method of customer satisfaction. Evaluating customer satisfaction throughout the entire service process rather than at specific stages is required to improve overall service quality. 


\subsection{Measuring Perceived and Actual Times}

Customers' perceived and actual time spent at specific stages during their shopping experience were measured. First, a customer visited a fast fashion store accompanied by an investigator. The customer was required to decide on a product to purchase before entering the shop. The investigator observed the customer's buying behaviour and measured the actual time spent at each stage of the shopping process. Investigators then surveyed customers about the perceived amount of time spent at each stage. The stages were classified as follows:

Stage A: The time it took to enter the shop and find the display cabinet where the predetermined product was kept

Stage B: The time it took to reach the display cabinet and select an item

Stage C: The time it took to use a fitting room

Stage D: The time it took to decide on an item and reach a cash register

Stage E: The time spent waiting in line

Stage F: The time it took to complete the transaction

Next, the differences between the actual measured times and customers' perceived times spent at each stage were evaluated as a dissatisfaction indicator. The indicator was calculated as the proportion of perceived time $\left(T_{1}\right)$ to actual time $\left(T_{2}\right)$. Dissatisfaction levels were evaluated as either 'very dissatisfied': ${ }^{T} / T_{2} \geq 1.5$, 'dissatisfied': $1.5>T_{1} / T_{2} \geq 1.0$, or 'slightly dissatisfied or no dissatisfaction': $1.0>T_{1} / T_{2}$. Depending on the second measure described in the next subsection, the answer could also be judged as 'no dissatisfaction' if a customer did not select a frustration factor at a stage.

\subsection{Multiple Choice Questionnaire}

A multiple choice questionnaire was completed by customers to identify factors which led to frustration during the shopping experience. As shown in Table 1, possible dissatisfaction factors are listed for each stage of the shopping experience, as described in section 2.1. The number of choices for each question ranges from five to eight, and allows for customers to make multiple selections. The answers to the questionnaire were then quantified and converted to either the number 1 , which meant selected, or 0 , which meant not selected by dummy variables.

\subsection{Developing the Customer Satisfaction Model}

Multiple regression analysis was used to integrate the results of the two measures discussed in sections 2.1 and 2.2. First, a regression model that linked dissatisfaction levels with dissatisfaction factors was obtained. The model considered each stage separately. The customer satisfaction model is shown in Eq. 1.

$$
Y=\beta_{0}+\beta_{1} x_{1}+\beta_{2} x_{2}+\cdots+\beta_{n} x_{n}+\varepsilon
$$


The explained variable $Y$ represents the proportion of perceived time $\left(T_{1}\right)$ to actual time $\left(T_{2}\right): T_{1} / T_{2}$. The independent variables $x_{1}, x_{2}, \ldots, x_{n}$ are known constants that represent the dissatisfaction factor derived from the answers to the questionnaire. The variables are quantified and converted to 1 , which means selected, or 0 , which means not selected by dummy variables as shown in section 2.2. In this model, the intercept coefficient $\beta_{0}$ is adopted as the value ' 1 '. Therefore, the explained variable $Y$ is ' 1 ' when all independent variables are ' 0 ', which means customers do not feel any dissatisfaction, as represented by $T_{1} / T_{2}=1$.

Table 1. Items from the Multiple Choice Questionnaire

\begin{tabular}{|c|c|}
\hline Stage & Items from the multiple choice questionnaire \\
\hline $\begin{array}{l}\text { Stage A: } \\
\text { The time it took to enter the } \\
\text { shop and find the display } \\
\text { cabinet where the } \\
\text { predetermined product was } \\
\text { kept }\end{array}$ & $\begin{array}{l}\text { 1. difficulty browsing the store due to crowds }\left(x_{1}\right) \\
\text { 2. could not find the predetermined item }\left(x_{2}\right) \\
\text { 3. there were no staff around to ask where the predetermined item was located }\left(x_{3}\right) \\
\text { 4. could not find the predetermined item due to confusing instructions from staff }\left(x_{4}\right) \\
\text { 5. the store was dusty and dirty with many unfolded clothes }\left(x_{5}\right) \\
6 . \text { other reasons }\left(x_{6}\right)\end{array}$ \\
\hline $\begin{array}{l}\text { Stage B: } \\
\text { The time it took to reach the } \\
\text { display cabinet and select an } \\
\text { item }\end{array}$ & $\begin{array}{l}\text { 1. could not buy the predetermined item because it was out of stock }\left(x_{1}\right) \\
\text { 2. the desired colour, pattern, or size was not readily visible }\left(x_{2}\right) \\
\text { 3. could not find the desired design }\left(x_{3}\right) \\
\text { 4. more expensive than expected }\left(x_{4}\right) \\
\text { 5. unable to decide on an item due to sizing uncertainty }\left(x_{5}\right) \\
\text { 6. could not reach the desired item due to crowds }\left(x_{6}\right) \\
\text { 7. the store was dusty and dirty with many unfolded clothes }\left(x_{7}\right) \\
\text { 8. other reasons }\left(x_{8}\right)\end{array}$ \\
\hline $\begin{array}{l}\text { Stage C: } \\
\text { The time it took to use a } \\
\text { fitting room }\end{array}$ & $\begin{array}{l}\text { 1. long wait time due to full fitting rooms }\left(x_{1}\right) \\
\text { 2. could not judge whether or not one was allowed to use the fitting rooms }\left(x_{2}\right) \\
\text { 3. there were no staff around to consult }\left(x_{3}\right) \\
\text { 4. there was trash or clothes hangers inside the fitting room }\left(x_{4}\right) \\
\text { 5. felt the fitting room was small and uncomfortable }\left(x_{5}\right) \\
6 \text {. other reasons }\left(x_{6}\right)\end{array}$ \\
\hline $\begin{array}{l}\text { Stage D: } \\
\text { The time it took to decide on } \\
\text { an item and reach a cash } \\
\text { register }\end{array}$ & $\begin{array}{l}\text { 1. difficulty reaching a cash register due to crowds }\left(x_{1}\right) \\
\text { 2. could not find where the cash registers were located }\left(x_{2}\right) \\
\text { 3. there were no staff around to ask where the cash registers were located }\left(x_{3}\right) \\
\text { 4. could not find the cash registers due to confusing instructions from staff }\left(x_{4}\right) \\
\text { 5. the store was dusty and dirty with many unfolded clothes }\left(x_{5}\right) \\
6 \text {. other reasons }\left(x_{6}\right)\end{array}$ \\
\hline $\begin{array}{l}\text { Stage E: } \\
\text { The time spent waiting in line }\end{array}$ & $\begin{array}{l}\text { 1. the line was long and processed slowly }\left(x_{1}\right) \\
\text { 2. could not find the end of the line }\left(x_{2}\right) \\
\text { 3. another customer cut the line }\left(x_{3}\right) \\
\text { 4. lack of attention to customer care, with no words such as, 'sorry to have kept you } \\
\text { waiting' }\left(x_{4}\right) \\
\text { 5. the cashier worked slowly }\left(x_{5}\right) \\
\text { 6. the counter was dusty and dirty }\left(x_{6}\right) \\
\text { 7. too few cash registers }\left(x_{7}\right) \\
\text { 8. other reasons }\left(x_{8}\right)\end{array}$ \\
\hline $\begin{array}{l}\text { Stage } \mathbf{F} \text { : } \\
\text { The time it took to complete } \\
\text { the transaction }\end{array}$ & $\begin{array}{l}\text { 1. staff were hard to hear }\left(x_{1}\right) \\
\text { 2. staff spoke too fast }\left(x_{2}\right) \\
\text { 3. artificial service }\left(x_{3}\right) \\
\text { 4. the cashier took a long time to pack the bought items }\left(x_{4}\right) \\
\text { 5. treated items roughly }\left(x_{5}\right) \\
\text { 6. the counter was dirty }\left(x_{6}\right) \\
\text { 7. the counter space was small }\left(x_{7}\right) \\
\text { 8. } \text { other reasons }\left(x_{8}\right)\end{array}$ \\
\hline
\end{tabular}


In addition, this paper set the parameters of $\beta_{1}, \beta_{2}, \ldots, \beta_{n}$ as positive values in order to prevent a factor from having unnatural effect of reducing the degree of dissatisfaction. When a parameter was estimated as a negative number, the corresponding dummy variable was removed from the model and the analysis was repeated. The estimation was repeated until all parameters became positive values.

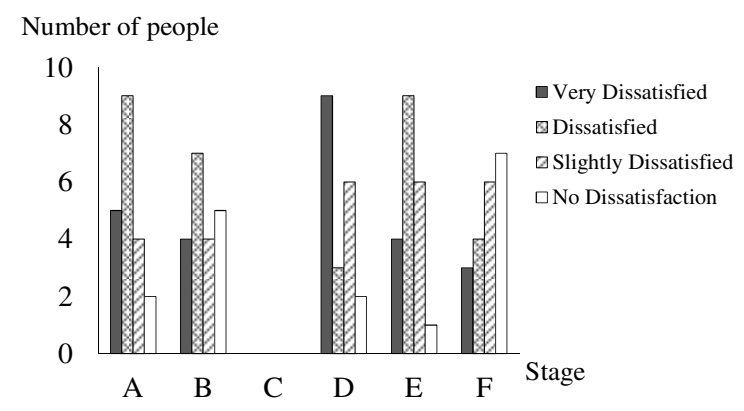

Fig. 1. Dissatisfaction levels at each stage of shopping

\section{$3 \quad$ Field Experiment}

\subsection{Implementation}

This section discusses how the proposed model was tested in an actual experiment at a fast fashion store. The experiment was conducted on weekdays during the busy shopping season between November and December in order to test the model in crowded store situations. A sample size of 20 students aged in their twenties was used. A limited age range was included in the study in order to control for the influence of ageing in the perception of time [17].

First, actual and perceived times were measured. Figure 1 shows the dissatisfaction levels at each stage of shopping, with the vertical axis representing the total number of people. In this experiment, Stage $C$ is removed from further analysis because there was only one consumer who used a fitting room. The results show that Stage D has the most 'very dissatisfied' ratings, although it is also observed in Stages A, B, E, and F. Furthermore, the stages all had similar numbers of 'very dissatisfied' and 'dissatisfied' ratings, the sum of these two values being 14, 11, 12, and 13 in Stages A, B, D, and $\mathrm{E}$, respectively. These results indicate that customers feel dissatisfaction at multiples stages during shopping.

Next, a multiple choice questionnaire was distributed to the target customers.

\subsection{Developing the Customer Satisfaction Model}

Using the results of the investigation shown in the previous section, a customer satisfaction model was developed using multiple regression analysis. The developed customer satisfaction models derived by Eq. 1 are shown in Eq. 2 to Eq. 6. The model 
considers each stage separately, as mentioned in section 2.2. The independent variables $x_{1}, x_{2}, \ldots, x_{n}$ correspond with the dissatisfaction factors shown in Table 1.

1. Stage A: The time it took to enter the shop and find the display cabinet where the predetermined product was kept.

$$
y=1.00+0.31 x_{1}+0.23 x_{2}+0.26 x_{3}+0.04 x_{5}
$$

As a result, it was estimated that $x_{1}$ (difficulty browsing the store due to crowds) was the most significant factor, followed by $x_{3}$ (there were no staff around to ask where the predetermined product was located), and $x_{2}$ (could not find the predetermined product).

2. Stage B: The time it took to reach the display cabinet and select an item.

$$
y=1.00+0.14 x_{1}+0.64 x_{6}
$$

The equation estimated that $x_{6}$ (could not reach the desired item due to crowds) was the most significant factor, followed by $x_{1}$ (could not buy the predetermined item because it was out of stock).

3. Stage C: The time it took to use a fitting room.

There was only one consumer who used a fitting room during the experiment, therefore Stage $\mathrm{C}$ was removed from further analysis.

4. Stage D: The time it took to decide on an item and reach a cash register.

$$
y=1.00+0.52 x_{1}
$$

The most significant factor was estimated as $x_{1}$ (difficulty reaching a cash register due to crowds).

5. Stage E: The time spent waiting in line.

$$
y=1.00+0.29 x_{1}+0.02 x_{2}+0.13 x_{5}+0.01 x_{7}
$$

It was estimated that $x_{1}$ (the line was long and processed slowly) was the most significant factor, followed by $x_{5}$ (the cashier worked slowly).

6. Stage F: The time it took to complete the transaction.

$$
y=1.00+0.23 x_{3}+0.13 x_{4}
$$

The variable $x_{3}$ (artificial service) was the most significant factor, followed by $x_{4}$ (the cashier took a long time to pack the purchased items).

The findings regarding Stage E (the time spent waiting in line) supported the findings by [9][13][14]. In addition, the independent factors with the highest parameters were all related to crowded situations, as demonstrated by $x_{1}$ (difficulty browsing the store due to crowds) in Stage A, $x_{6}$ (could not reach the desired item due to crowds) in Stage $\mathrm{B}$, and $x_{1}$ (difficulty reaching a cash register due to crowds) in Stage D. The results indicated that dissatisfaction factors were not only related to waiting, but also other situations encountered while shopping. 


\section{Multi-agent Simulation}

A simulation model was developed on a software named artisoc and the proposed customer satisfaction model was incorporated into a multi-agent simulation model. Figure 2 shows the implemented store layout and item locations. In this paper, customers, store staff, and cabinet agents were implemented and the store space was about 500 squire meters. The action model for customers was determined using the following rules: (1) avoid passing through aisles, (2) exploring desired product categories, and (3) waiting in line at cash registers. Each rule was implemented by the program using the results derived from section 3 .

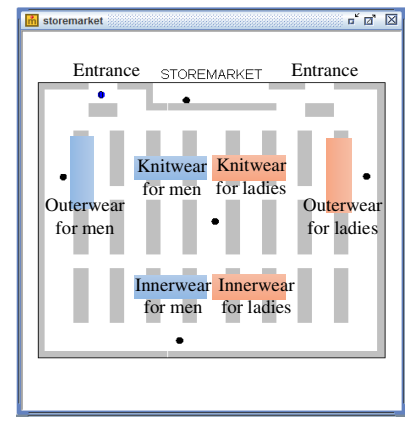

Fig. 2. Store layout and item location implemented by artisoc

This paper examined two conditions. The first considered staff assignments and task priorities as usual. The second changed staff assignments by moving one staff member from the sales floor to the cash register. Additionally, the rule regarding the limitation of working area was removed. The results were then evaluated and compared with the proportion of perceived time $\left(T_{1}\right)$ to actual time $\left(T_{2}\right): T_{1} / T_{2}$. The simulation was repeated 50 times.

The results showed that the value of $T_{1} / T_{2}$ was 1.11 for the first condition and 1.07 for the second condition. This confirmed that changing the priority and assignment rules derived from the proposed model improved customer satisfaction.

\section{Conclusion}

This paper proposed a customer satisfaction model to effectively manage staff task priorities in fast fashion service. The experiment was conducted at an actual store and validated the model. The results indicated the stages during shopping where customers experienced the greatest dissatisfaction, and which factors caused this dissatisfaction. Furthermore, multi-agent simulation was implemented using the results of the experiment, and confirmed that customer satisfaction levels increased after introducing task prioritisation and staff assignment changes. Applying the proposed evaluation model to other cases and testing it through further simulation are the next steps of this study. 
Acknowledgements. This work was partially supported by JSPS KAKENHI Grantin-Aid for Young Scientists (B) Number 26730159.

\section{References}

1. Fernie, J.: Retail Logistics. In: Bruce, M., Moore, C., Birtwistle, G. (eds.) International Retail Marketing, pp. 39-63. Butterworth-Heinemann, Oxford (2004)

2. Bearden, W.O., Teel, J.E.: Selected Determinants of Consumer Satisfaction and Complaint Reports. Journal of Marketing Research 20(1), 21-28 (1983)

3. Iacobucci, D., Ostrom, A.: Distinguishing Service Quality and Customer Satisfaction: The Voice of the Consumer. Journal of Consumer Psychology 4(3), 277-303 (1995)

4. Taylor, S.A., Baker, T.L.: An Assessment of the Relationship between Service Quality and Customer Satisfaction in the Formation of Consumers' Purchase Intentions. Journal of Retailing 70(2), 163-178 (1994)

5. Sureshchandar, G.S., Rajendran, C., Anantharaman, R.N.: The Relationship between Service Quality and Customer Satisfaction - A Factor Specific Approach. The Journal of Service Marketing 16(4), 363-379 (2002)

6. Spreng, R.A., Mackoy, R.D.: An Empirical Examination of a Model of Perceived Service Quality and Satisfaction. Journal of Retailing 70(2), 201-214 (1996)

7. McGuire, K.A., Kimes, S.E., Lynn, M., Pullman, M.E., Lloyd, R.C.: A Framework for Evaluating the Customer Wait Experience. Journal of Service Management 21(3), 269-290 (2010)

8. Luo, W., Liveratore, M.J., Nydick, R.L., Chung, Q.B., Sloane, E.: Impact of Process Change on Customer Perception of Waiting Time: A Field Study. The International Journal of Management Science Omega 32(1), 77-83 (2004)

9. Pruyn, A., Smidts, A.: Effects of Waiting on the Satisfaction with the Service: Beyond Objective Time Measures. International Journal of Research in Marketing 15(4), 321-334 (1998)

10. Kumar, P.: The Competitive Impact of Service Process Improvement: Examining Customers' Waiting Experiences in Retail Markets. Journal of Retailing 81(3), 171-180 (2005)

11. Shimmura, T., Kaihara, T., Fujii, N., Takenaka, T.: Improving Customer's Subjective Waiting Time Introducing Digital Signage. Advances in Production Management Systems. Competitive Manufacturing for Innovative Products and Services, IFIP Advances in Information and Communication Technology. 398, 385-391 (2013)

12. Gail, T., Lucey, S.: A Field Study Investigating the Effect of Waiting Time on Customer Satisfaction. The Journal of Psychology 131(6), 655-660 (1997)

13. Taylor, S.: Waiting for Service: The Relationship between Delays and Evaluations of Service. Journal of Marketing 58(2), 56-69 (1994)

14. Davis, M.M.: A Framework for Relating Waiting Time and Customer Satisfaction in a Service Operation. Journal of Services Marketing 4(1), 61-69 (1990)

15. Chebat, J.C., Filiatrault, P.: The Impact of Waiting in Line on Consumers. The International Journal of Bank Marketing 11(2), 35-40 (1993)

16. Murdick, R.G., Render, B., Russell, R.S.: Service Operations Management. Allyn and Bacon, Boston (1990)

17. Wada, H., Murata, W.: Duration Judgments in Elderly-Hospitalized Persons: Aging and Subjective Time Passages. Annual Report Gerontological Research 17, 79-85 (2001) (in Japanese) 